\title{
ESCA Studies of Protonation in Polyaniline
}

\author{
E. T. KANG, ${ }^{a}$ K. G. NEOH, ${ }^{a}$ and K. L. TAN ${ }^{b}$ \\ ${ }^{\mathrm{a}}$ Department of Chemical Engineering and ${ }^{\mathrm{b}}$ Department of Physics, \\ National University of Singapore, \\ Kent Ridge, Singapore 0511
}

(Received March 27, 1989)

\begin{abstract}
The structural changes associated with the protonation of polyemeraldine base by various protonic acids were studied by X-ray photoelectron spectroscopy (XPS). The imine, amine and positively charged nitrogen corresponding to a particular oxidation state and protonation level were quantitatively differentiated in the properly deconvoluted N1s core-level spectrum. The actual degree of protonation in the $\mathrm{HCl}$ and $\mathrm{HBr}$ complexes was determined from the halogen anion core-level component. The anion in the $\mathrm{H}_{2} \mathrm{SO}_{4}$ complex was found to be the monovalent $\mathrm{HSO}_{4}{ }^{-}$species. Treatment of the $\mathrm{HBr}, \mathrm{HNO}_{3}$, and $\mathrm{H}_{2} \mathrm{SO}_{4}$ protonated polyemeraldine with $\mathrm{HCl}$ readily resulted in the exchange of the anion species.

KEY WORDS X-Ray Photoelectron Spectroscopy / Polyemeraldine /

Protonation / Chemical Structure /
\end{abstract}

Recent interest in the electroactive polymers ${ }^{1}$ has resulted in renewed interest ${ }^{2-4}$ in the century-old ${ }^{5}$ aniline family of polymers. The conductive polyaniline complexes can be prepared either by chemical ${ }^{4}$ or electrochemi$\mathrm{cal}^{6,7}$ polymerization and oxidation. The polymers are basically poly $(p$-phenylene amine imine)s in which the oxidation state of the polymer can be varied from the fully reduced poly ( $p$-phenylene amine) or "leucoemeraldine" to the fully oxidized poly $(p$-phenylene imine) or "pernigraniline". The $50 \%$ oxidized polymer has been termed an "emeraldine base". Each oxidation state can exist in the form of its base or protonated form by treatment of the base with an acid. ${ }^{2,3}$

The structures of the polyaniline complexes have been studied by various analytical techniques. ${ }^{8-11} \mathrm{~A}$ number of oligomeric model compounds of aniline have also been investigated. ${ }^{12-15} \mathrm{~A}$ number of recent reports have been devoted to the use of electron spectroscopy for chemical analysis (ESCA) or X-ray photoelectron spectroscopy (XPS) technique to characterize polyanilines. ${ }^{7,12,16-19}$ However, the chemical structure associated with a particular redox state, such as the relative amounts of benzoid amine, quinoid imine and positively charged nitrogen, has yet to be determined quantitatively and unambiguously. The present XPS study indicates that the three nitrogen species can be quantitatively differentiated in the N1s core-level spectrum. This allow the investigation of structural changes associated with protonation and deprotonation of polyaniline.

\section{EXPERIMENTAL}

\section{Polymer Samples}

Polyemeraldine hydrochloride was prepared as a dark green powder by the oxidative polymerization of aniline in $1.2 \mathrm{M}$ aqueous $\mathrm{HCl}$ with ammonium persulphate, according to the method published in the literature. ${ }^{2-4}$ The product was deprotonated to various degrees or to the polyemeraldine base by treatment with varying amount of $0.1 \mathrm{M} \mathrm{NaOH}$. 
The polyemeraldine base was then reprotonated to various extents by equilibrating the base in aqueous $\mathrm{HCl}$ solutions at various $\mathrm{pH}$. All samples were dried under reduced pressure for at least $48 \mathrm{~h}$ before use. The electrical conductivity of the samples was measured using the standard collinear four-probe and two-probe techniques on compressed pellets. For comparison purposes, polymerization and protonation were also carried out in other protonic acid media, such as aqueous $\mathrm{HBr}$, $\mathrm{HNO}_{3}$, and $\mathrm{H}_{2} \mathrm{SO}_{4}$, following the same procedures described above.

\section{XPS Measurements}

XPS measurements were carried out on a VG ESCALAB MkII spectrometer with a $\mathrm{MgK} \alpha \mathrm{X}$-ray source (1253.6 eV photons). The powder samples were mounted on sample studs with a double-sided adhesive tape. All core-level spectra were referenced to the Cls neutral carbon peak at $284.6 \mathrm{eV}$. The $\mathrm{X}$-ray power supply was run at $12 \mathrm{kV}$ and $10 \mathrm{~mA}$. Pressure in the analysis chamber during the scans was approximately $10^{-8}$ mbar or less. All core-level spectra were curve-fitted with Gaussian component peaks. The peak width (full width at half maximum or f.w.h.m.) was maintained constant for all components in a particular spectrum. The peak area ratios for various elements were corrected by experimentally determined instrumental sensitivity factors and may be subjected to $\pm 10 \%$ error. Since the surface compositions for all of the samples studied agreed fairly well with the bulk compositions obtained from chemical analysis, the present XPS results should be representative of bulk properties.

\section{RESULTS AND DISCUSSION}

\section{Protonation by $\mathrm{HCl}$}

The majority of studies on the protonation of polyaniline involve the use of hydrochloric acid. Previous XPS studies have shown that the N1s core-level spectrum of the polyemeral- dine base consists of a broad peak with a line width (f.w.h.m.) in the order of $2.4 \mathrm{eV} .^{16,17}$ Upon protonation with $\mathrm{HCl}$, the line width is substantially reduced and a high binding energy (B.E.) shoulder or tail becomes prominent. ${ }^{16-18}$

Figure 1(a) to Figure 1(d) show the N1s XPS core-level spectra of polyemeraldine at various extent of protonation by $\mathrm{HCl}$. The extent of $\mathrm{HCl}$ incorporation in each sample was determined from the ratio of chlorine and nitrogen peak area, after correcting with instrumental sensitivity factors. Three inequivalent nitrogens can be discerned in the N1s spectrum of each complex. The two major peaks at B.E. of $399.3 \pm 0.1 \mathrm{eV}$ and $398.1 \pm$ $0.1 \mathrm{eV}$ and with a line width of $1.60 \mathrm{eV}$ are assigned to the amine and imine structures, respectively, based on the supporting evidence given below. First of all, one would expect a more electron-rich environment for the imine nitrogen and thus a corresponding lowering of the observed B.E. In the case of polyemeraldine base (Figure 1(a)), the two major components have nearly the same area, suggesting that about equal amounts of imine and amine nitrogens are present in the polyemeraldine base. This is in agreement with the polyemeraldine structure proposed by MacDiarmid et $a l^{2}$ A slightly reduced amount of the imine structure observed in the present sample is attributable to the presence of a trace amount of positively charged nitrogen, ${ }^{16}$ as indicated by the residual N1s high B.E. tail. The latter probably arises from the presence of a trace amount of chloride anion as suggested by the $\mathrm{Cl} 2 \mathrm{p}$ core-level spectrum of the sample. Furthermore, the surface of this sample may have also been oxidized to a small extent by oxygen, as suggested by the presence of a weak Ols core-level spectrum. The presence of surface oxidation has also been observed in polyaniline prepared electrochemically, ${ }^{7}$ as well in other polymers with a conjugated backbone. $^{20}$

The peak assignments are further supported 


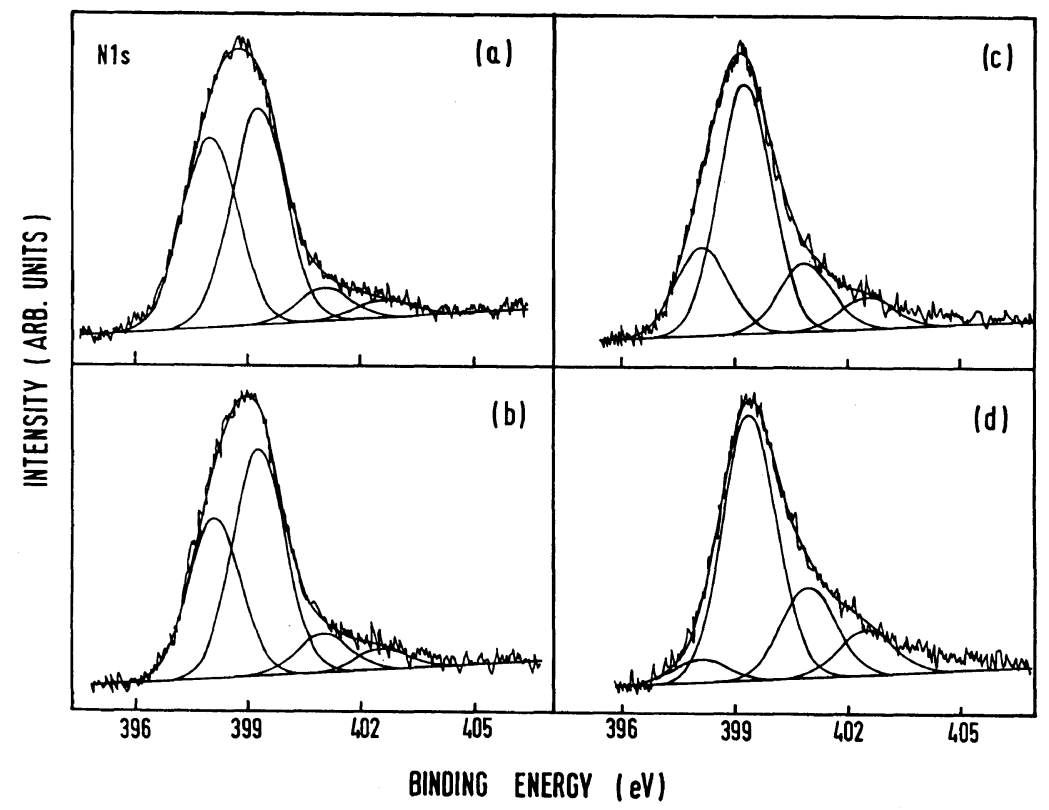

Figure 1. Nls XPS core-level spectra of (a) polyemeraldine base, and (b) to (d) polyemeraldine hydrochloride at a $\mathrm{Cl} / \mathrm{N}$ ratio of $0.17,0.36$, and 0.44 , respectively.

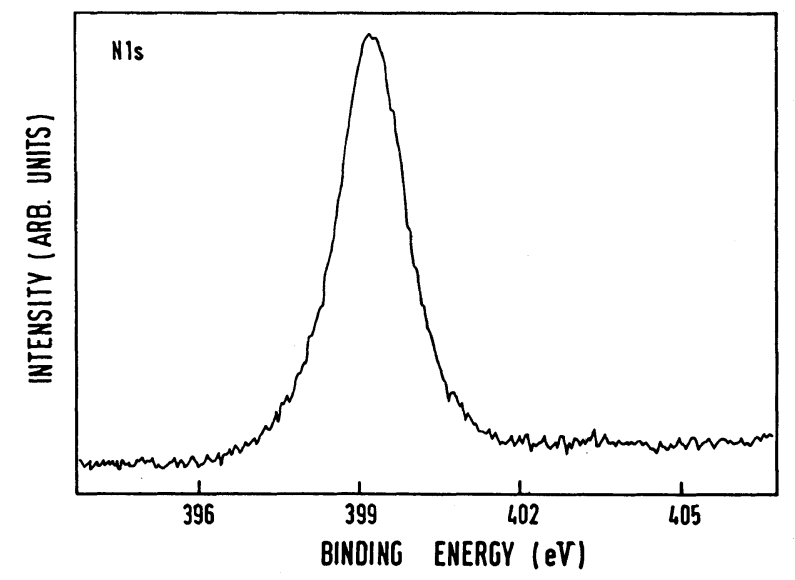

Figure 2. N1s XPS core-level spectrum of the fully reduced polyleucoemeraldine.

by the fact that the fully reduced polyleucoemeraldine which consists of only benzoid rings and amine nitrogen, ${ }^{21}$ has only a single N1s environment at $399.3 \mathrm{eV}$, with a line width of about $1.45 \mathrm{eV}$ (Figure 2). Furthermore, comparison of the Nls peak B.E. between pyrrolylium nitrogen in polypyrrole (-NH- structure) $)^{22}$ and that of the pyri- dinium nitrogen in poly(vinyl pyridine) $(-\mathrm{N}=$ structure) reveals that the latter is lowered by $1.1 \mathrm{eV}(399.5 \mathrm{eV}$ versus $398.4 \mathrm{eV})$. Finally, dehydrogenation of the pyrrolylium nitrogen in polypyrrole, followed by rearrangement of the pyrrole bonds to satisfy the three nitrogen valences can result in a more electron-rich imine-like structure and a corresponding neg- 


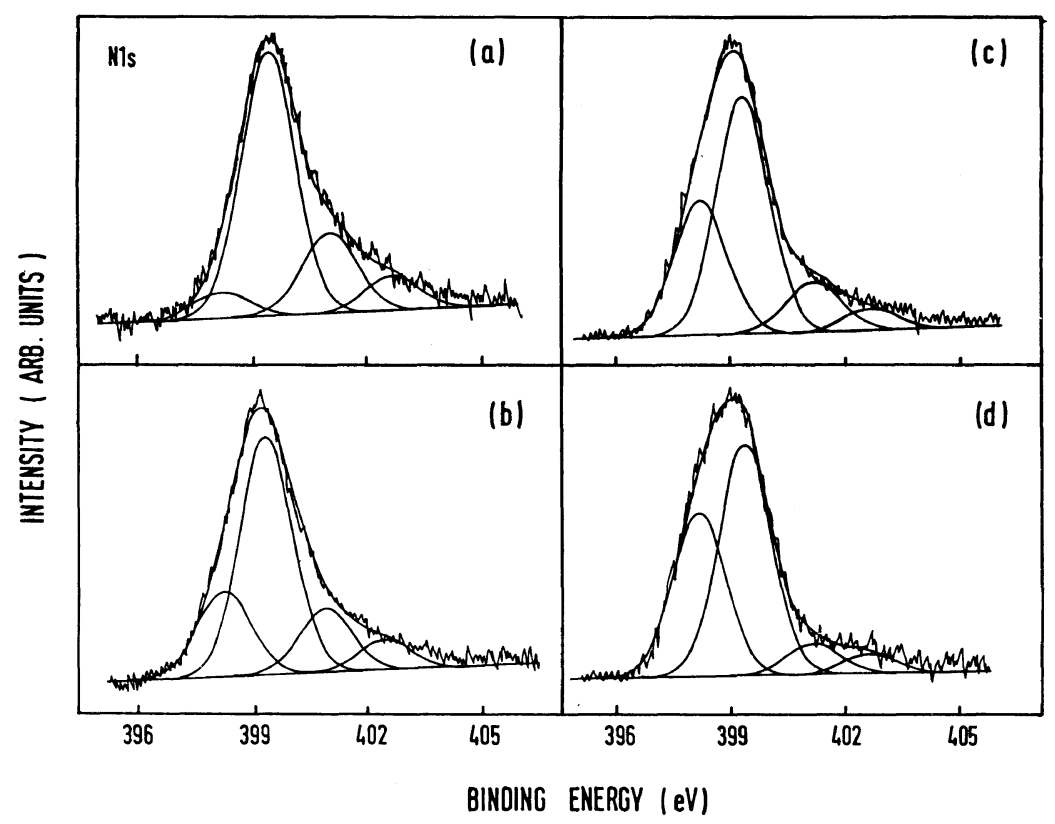

Figure 3. N1s XPS core-level spectra of polyemeraldine hydrochloride at various stages of deprotonation with $\mathrm{Cl} / \mathrm{N}$ ratios of (a) 0.41 , (b) 0.21 , (c) 0.14 , and (d) 0.08 .

ative shift of the N1s B.E. by about $1.3 \mathrm{eV} .^{23}$

Figure 1(a) to Figure 1(d) reveal that upon progressive protonation of polyemeraldine base, the amount of imine structure decreases steadily while the high B.E. tail attributable to the positively charged nitrogen ${ }^{16,18}$ becomes more and more prominent. This is entirely consistent with the reports ${ }^{2,3}$ that the imine repeating units of the polyemeraldine base are preferentially protonated by $\mathrm{HCl}$. The present peak assignments are further confirmed by changes in the N1s line-shape during deprotonation of polyemeraldine hydrochloride by $\mathrm{NaOH}$. Figure 3(a) to Figure 3(d) show the recovery of the imine structure and reduction of the high B.E. tail upon progressive deprotonation of polyemeraldine hydrochloride by $\mathrm{NaOH}$. Table I summarizes the changes in the proportion of the three nitrogen species and electrical conductivity of the polyemeraldine samples at various stages of protonation by $\mathrm{HCl}$.

Based on the present peak assignments, the data in Table I show that the proportion of the amine structure can increase above $50 \%$, especially at high protonation levels. Furthermore, in most of the present complexes, the fraction of positively charged nitrogen is lower than the amount of protonation determined from the overall $\mathrm{Cl} / \mathrm{N}$ ratio. Similar observation has also been reported for the electrochemically polymerized polyemeraldine hydrochloride. ${ }^{18}$ The $\mathrm{Cl} 2 \mathrm{p}$ core-level spectrum for all of the present complexes can be fitted with $\mathrm{Cl} 2 \mathrm{p}_{1 / 2}$ and $\mathrm{Cl} 2 \mathrm{p}_{3 / 2}$ components at B.E. positions corresponding to those for covalent and ionic chlorine species. The $\mathrm{Cl} 2 \mathrm{p}_{3 / 2}$ B.E. corresponding to these two species are at about $200.2 \mathrm{eV}$ and $197.2 \mathrm{eV}$, respectively. The presence of chlorine with covalent character has been widely observed in protonated polyaniline and related model compounds. $^{7,12}$ The proportions of the two chlorine species for the present samples at various extent of protonation are also included in Table I. The presence of covalent chlorine, 
Table I. Surface stoichiometries and changes in the chemical structures of polyemeraldine base on progressive protonation by $\mathrm{HCl}$

\begin{tabular}{|c|c|c|c|c|c|c|c|}
\hline \multirow{2}{*}{ Sample } & \multicolumn{3}{|c|}{ XPS surface stoichiometries ${ }^{a}$} & \multirow{2}{*}{$\begin{array}{c}=\mathrm{N}- \\
(B . E .=398.1 \pm 0.1 \mathrm{eV})\end{array}$} & \multirow{2}{*}{$\begin{array}{c}\begin{array}{c}\text { Proportions }^{\mathrm{b}} \text { of } \\
-\mathrm{NH}-\end{array} \\
(\mathrm{B} . \mathrm{E} .=399.3 \pm 0.1 \mathrm{eV})\end{array}$} & \multirow{2}{*}{$\begin{array}{c}\mathrm{N}^{+} \\
(\text {B.E. }>401 \mathrm{eV})\end{array}$} & \multirow{2}{*}{$\begin{array}{l}\text { Conductivity } \\
\sigma / \mathrm{S} \mathrm{cm}^{-1}\end{array}$} \\
\hline & Total $\mathrm{Cl} / \mathrm{N}$ & $-\mathrm{Cl} / \mathrm{N}$ & $\mathrm{Cl}^{-} / \mathrm{N}$ & & & & \\
\hline 1 & 0.05 & 0.04 & 0.01 & 0.40 & 0.51 & 0.09 & $10^{-10}$ \\
\hline 2 & 0.12 & 0.04 & 0.08 & 0.38 & 0.51 & 0.11 & $2 \times 10^{-6}$ \\
\hline 3 & 0.17 & 0.04 & 0.13 & 0.35 & 0.51 & 0.14 & $6 \times 10^{-5}$ \\
\hline 4 & 0.28 & 0.05 & 0.23 & 0.31 & 0.51 & 0.18 & $6 \times 10^{-3}$ \\
\hline 5 & 0.31 & 0.06 & 0.25 & 0.27 & 0.53 & 0.20 & $1 \times 10^{-2}$ \\
\hline 6 & 0.36 & 0.07 & 0.29 & 0.20 & 0.57 & 0.23 & $1 \times 10^{-1}$ \\
\hline 7 & 0.44 & 0.10 & 0.34 & 0.06 & 0.64 & 0.30 & 2 \\
\hline
\end{tabular}

a Based on corrected $\mathrm{N} 1 \mathrm{~s}$ and $\mathrm{C} 12 \mathrm{p}$ core-level spectral area ratios.

b Based on the curve-fitted N1s core-level spectrum.

together with the increase in the amine structure at high protonation levels, suggest the addition of $\mathrm{HCl}$ to the imine repeating units, resulting in an increase in the benzoid/quinoid ratio. ${ }^{10,12}$ Finally, the data in Table $I$ indicate that a close balance in charges can indeed be observed based on the amount of positively charged nitrogen and actual amount of chloride anion present. Thus, the degree of protonation cannot be accurately determined based on total chlorine balance alone. The presence of a localized unit positive charge on the nitrogen is consistent with the concept of nitrogenonium ion polymer of MacDiarmid et al., ${ }^{24}$ although other studies suggest the presence of delocalized radical cations. ${ }^{17}$

Finally, a comparison of N1s core-level spectra in Figure 1 and Figure 3 reveals that the chemical structure of a polyemeraldine hydrochloride sample at a particular $\mathrm{Cl} / \mathrm{N}$ ratio can vary somewhat, depending on whether the sample is obtained by protonation or deprotonation. This is partially attributable to the fact that covalently bonded chlorine forms only at a high protonation level and is removed only from a highly deprotonated sample.

\section{Protonation by $\mathrm{HBr}$}

The behavior and structural changes in polyemeraldine during protonation by $\mathrm{HBr}$ are similar to those during protonation by $\mathrm{HCl}$ described above. The polyemeraldine hydrobromide, as prepared by the oxidative polymerization of aniline with ammonium persulphate in the presence of $\mathrm{HBr}$, however, contains a high proportion of covalently bonded bromine atoms. Figure 4(a) and Figure 4(b) show the respective $\mathrm{N} 1 \mathrm{~s}$ and $\mathrm{Br} 3 \mathrm{~d}$ XPS core-level spectra of such a sample with a total $\mathrm{Br} / \mathrm{N}$ ratio of about $0.89\left(\mathrm{Br}^{-} / \mathrm{N}=0.35\right.$ and $\left.-\mathrm{Br} / \mathrm{N}=0.54\right)$. Thus, as much as $60 \%$ of the bromine atoms can become covalently bonded to the polymer. Again, fairly good balance between the amounts of bromide anion and positively charged nitrogen is observed. Upon progressive deprotonation with $\mathrm{NaOH}$, the bromide anion is preferentially removed while the covalent bromine remains almost intact. The N1s and Br3d XPS core-level spectra for a deprotonated sample with a total $\mathrm{Br} / \mathrm{N}$ ratio of about 0.50 are shown in Figure $4(\mathrm{c})$ and Figure 4(d), respectively. Thus, most of the bromide anion has been removed during deprotonation and is accompanied by a corresponding recovery of the imine structure. The electrical conductivity of the sample decreased correspondingly from about $0.3 \mathrm{~S} \mathrm{~cm}^{-1}$ to less than $10^{-9} \mathrm{~S} \mathrm{~cm}^{-1}$. The somewhat lower conductivity observed in the pristine polyemeraldine hydrobromide as compared to that of the polyemeraldine hydrochloride is at least 


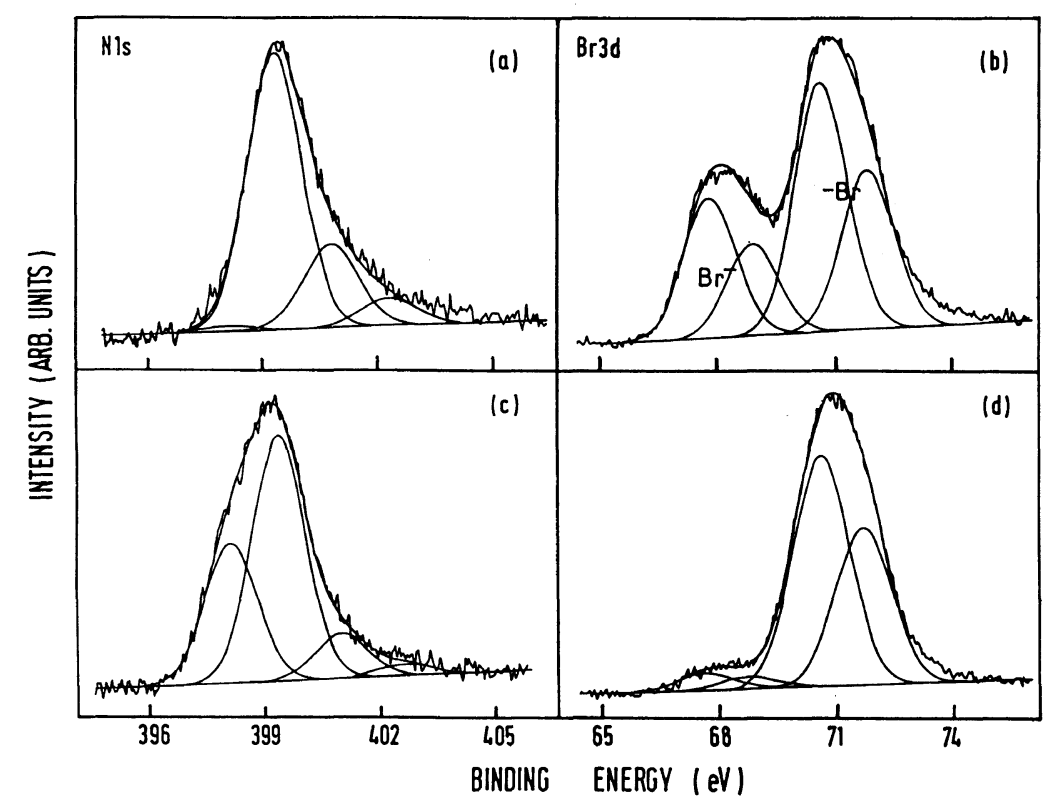

Figure 4. Curve-fitted (a) N1s and (b) Br3d XPS core-level spectra for polyemeraldine hydrobromide at a $\mathrm{Br} / \mathrm{N}$ ratio of 0.89 and the corresponding spectra ((c) and (d)) of the sample after deprotonation to a $\mathrm{Br} / \mathrm{N}$ ratio of 0.50 .

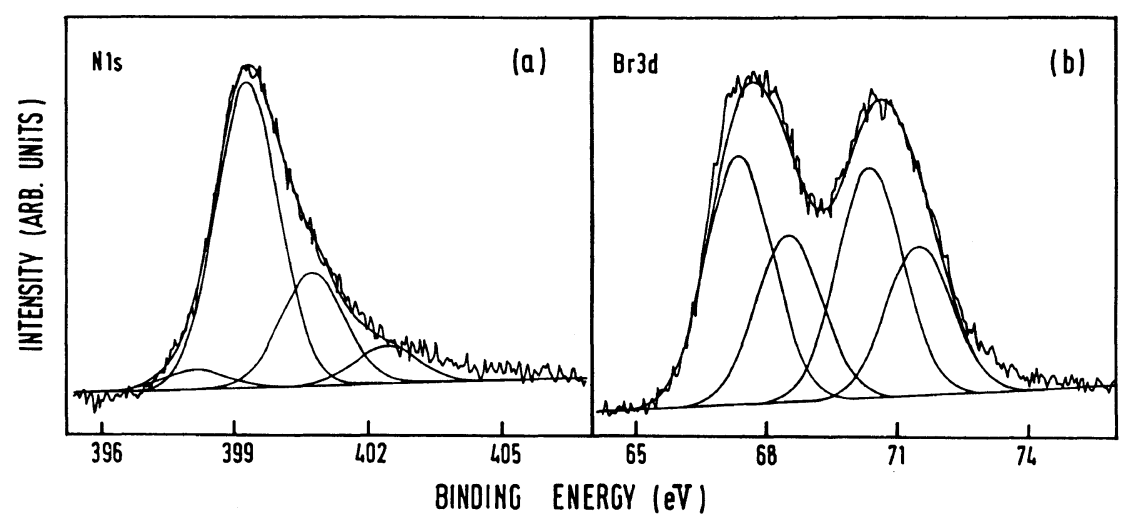

Figure 5. Curve-fitted (a) N1s and (b) Br3d XPS core-level spectra for polyemeraldine hydrobromide after extraction with chloroform to a $\mathrm{Br} / \mathrm{N}$ ratio of 0.55 .

partially attributable to the presence of a high proportion of covalently bonded bromine. In polyemeraldine hydrochloride, the conversion of chloride ions to covalently bonded chlorine has been found to cause a decrease in conductivity. ${ }^{25}$

Of particular interest is the preferential removal of a substantial amount of the polymer with covalently bonded bromine upon extraction of the complex with chloroform. The UVvisible absorption spectrum of the chloroform wash reveals the presence of a dissolved polymer, as suggested by the presence of a broad absorption band in the visible region. Figure 5(a) and Figure 5(b) show the respective N1s and $\mathrm{Br} 3 \mathrm{~d}$ core-level spectra of a chloroform 


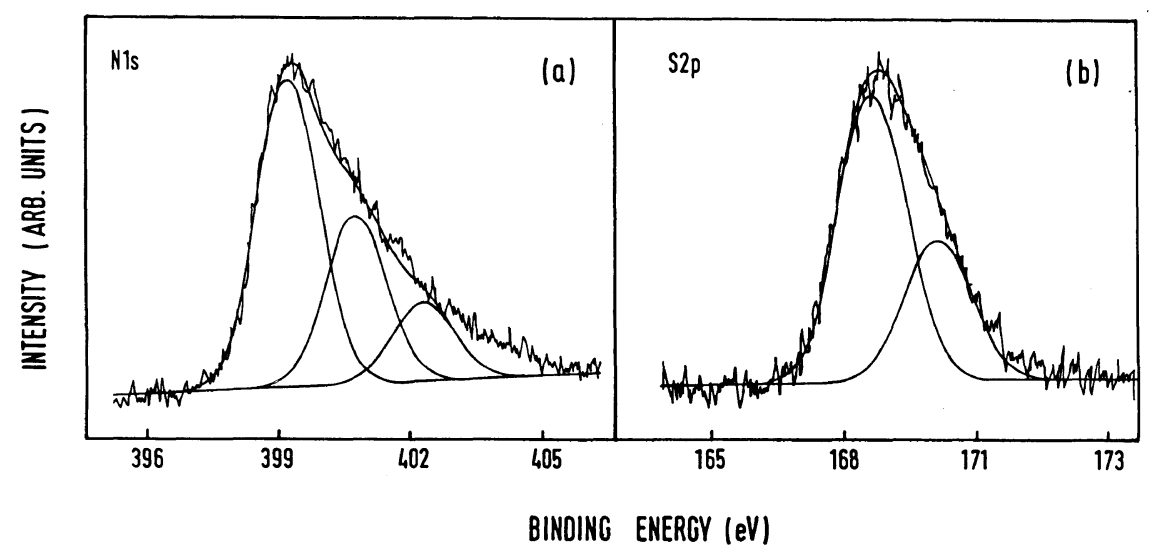

Figure 6. Curve-fitted (a) $\mathrm{N} 1 \mathrm{~s}$ and (b) $\mathrm{S} 2 \mathrm{p}$ core-level spectra for a $\mathrm{H}_{2} \mathrm{SO}_{4}$ protonated polyemeraldine with a $\mathrm{S} / \mathrm{N}$ ratio of 0.52 .

Table II. Surface stoichiometries and chemical structures of $\mathrm{H}_{2} \mathrm{SO}_{4}$ protonated polymeraldine at various extents of protonation

\begin{tabular}{|c|c|c|c|c|c|}
\hline \multirow{2}{*}{ Sample } & \multirow{2}{*}{$\frac{\text { XPS surface stoichiometries }^{\mathrm{a}}}{\mathrm{S} / \mathrm{N} \text { ratio }}$} & \multirow{2}{*}{$\begin{array}{c}=\mathrm{N}- \\
(\text { B.E. }=398.1 \pm 0.1 \mathrm{eV})\end{array}$} & \multirow{2}{*}{$\begin{array}{c}\begin{array}{c}\text { Proportions }^{\mathrm{b}} \text { of } \\
-\mathrm{NH}-\end{array} \\
(\mathrm{B} . \mathrm{E} .=399.3 \pm 0.1 \mathrm{eV})\end{array}$} & \multirow{2}{*}{$\begin{array}{c}\mathrm{N}^{+} \\
(\text {B.E. }>401 \mathrm{eV})\end{array}$} & \multirow{2}{*}{$\begin{array}{l}\text { Conductivity } \\
\sigma / \mathrm{S} \mathrm{cm}^{-1}\end{array}$} \\
\hline & & & & & \\
\hline 1 & 0.52 & 0.0 & 0.55 & 0.45 & 3 \\
\hline 2 & 0.20 & 0.23 & 0.55 & 0.22 & $7 \times 10^{-2}$ \\
\hline 3 & 0.16 & 0.24 & 0.54 & 0.21 & $1 \times 10^{-2}$ \\
\hline 4 & 0.01 & 0.42 & 0.48 & 0.09 & $10^{-10}$ \\
\hline
\end{tabular}

a Based on corrected N1s and S2p core-level spectral area ratios.

b Based on the curve-fitted N1s core-level spectrum.

treated sample in which the total $\mathrm{Br} / \mathrm{N}$ ratio has been reduced to about 0.55 . The $\mathrm{Br}^{-} / \mathrm{N}$ ratio, however, was not affected by this treatment. Thus, treatment of polyemeraldine hydrobromide with chloroform results in a substantial increase in the ionic to covalent bromine ratio. This in turn causes the electrical conductivity of the complex to increase by more than a factor of two.

\section{Protonation by $\mathrm{H}_{2} \mathrm{SO}_{4}$}

The chemical structure of $\mathrm{H}_{2} \mathrm{SO}_{4}$ protonated polyemeraldine and the structural changes associated with its step-wise deprotonation, as revealed by the N1s core-level line shape, are similar to those observed in the $\mathrm{HCl}$ or $\mathrm{HBr}$ protonated sample. Figure 6(a) and Figure 6(b) show the respective N1s and $S 2 p$ core-level spectra for a typical $\mathrm{H}_{2} \mathrm{SO}_{4}$ protonated polyemeraldine. In this case, almost all the imine units are protonated and transformed into positively charged nitrogens. The B.E. of $\mathrm{S} 2 \mathrm{p}_{3 / 2}$ component at about $168.6 \mathrm{eV}$ is consistent with a single sulphate environment. ${ }^{26}$ However, the valency of the sulphate anion associated with the nitrogenonium cation may require special consideration. In electrochemically prepared $\mathrm{H}_{2} \mathrm{SO}_{4}$ samples, the presence of $\mathrm{SO}_{4}{ }^{-2}$ and $\mathrm{HSO}_{4}{ }^{-}$anion species were considered but not resolved. ${ }^{18}$ The present work attempts to solve this problem by stoichiometry and charge neutrality. Table II summarizes the proportions of the three nitrogen species at various protonation levels for $\mathrm{H}_{2} \mathrm{SO}_{4}$ doped samples. A close balance between the number of unit positively charged 
nitrogens and number of sulphur atoms is observed. Thus, the sulphate groups are of the univalent anion species with the form of $\mathrm{HSO}_{4}{ }^{-}$. In the totally deprotonated sample (Sample 4 in Table II), the presence of some excess positive charge on nitrogen is probably associated with the presence of surface oxidation in the deprotonated polyemeraldine.

\section{Comparison of Acid Strength}

The strength of various acids toward the protonation of polyemeraldine was briefly compared. The $\mathrm{HBr}, \mathrm{H}_{2} \mathrm{SO}_{4}$, and $\mathrm{HNO}_{3}$ protonated samples were treated with $1 \mathrm{M} \mathrm{HCl}$. In all cases, this resulted in a complete exchange of anionic species in the complex by chloride anions. In the case of $\mathrm{H}_{2} \mathrm{SO}_{4}$ and $\mathrm{HNO}_{3}$ protonated samples, for example, $\mathrm{HCl}$ treatment resulted in a complete lost of the $S 2 p$ core-level signal and $\mathrm{N} 1 \mathrm{~s}$ core-level signal (B.E. $\sim 406.3 \mathrm{eV}$ ) due to the respective sulphate and nitrate species. A final $\mathrm{Cl} / \mathrm{N}$ ratio of about 0.42 was observed in both samples. This readily suggests that most of the imine repeating units in these two complexes remain intact.

In the case of polyemeraldine hydrobromide with initial $\mathrm{Br}^{-} / \mathrm{N}$ and $-\mathrm{Br} / \mathrm{N}$ ratios of 0.35 and 0.54 , respectively, the XPS results indicate that treatment with $\mathrm{HCl}$ results in a complete replacement of the bromide anion. However, almost all the covalently bonded bromine remain intact. This treated sample thus takes on a $\mathrm{Cl} / \mathrm{N}$ ratio of only about 0.30 , with most of the chlorine existing as chloride anion. It has been well established that the imine nitrogen of polyemeraldine base are preferentially protonated by $\mathrm{HCl}^{2}$ Thus, the fact that the $\mathrm{Cl} / \mathrm{N}$ ratio in the present $\mathrm{HCl}$ treated polyemeraldine hydrobromide remains substantially below the ideal value of 0.5 and is similar to the original $\mathrm{Br}^{-} / \mathrm{N}$ ratio readily suggest that covalent bromine formation must also result in a substantial reduction in the proportion of the imine repeating units in the original complex.

\section{CONCLUSIONS}

XPS technique was used to elucidate the structural changes during the protonation of polyemeraldine by $\mathrm{HCl}, \mathrm{H}_{2} \mathrm{SO}_{4}$, and $\mathrm{HBr}$. The proportions of imine, amine and positively charged nitrogen associated with a particular oxidation state and degree of protonation have been determined quantitatively and unambiguously from the properly curve-fitted N1s core-level spectrum. The presence of covalently bonded chlorine and bromine indicates that the actual degree of protonation in $\mathrm{HCl}$ and $\mathrm{HBr}$ complexes should not be determined from the overall halogen balance.

\section{REFERENCES}

1. See for example, in "Handbook of Conducting Polymers," Vols. I and II, T. Skotheim, Ed, Marcel Dekker, New York, N. Y., 1986.

2. J. C. Chiang and A. G. MacDiarmid, Synth. Metals, 13, 193 (1986).

3. A. G. MacDiarmid, J. C. Chiang, A. F. Richter, and A. J. Epstein, Synth. Metals, 18, 285 (1987).

4. S. P. Armes and J. F. Miller, Synth. Metals, 23, 385 (1988).

5. A. G. Green and A. E. Woodhead, J. Chem. Soc., 2388 (1910).

6. A. F. Diaz and J. A. Logan, J. Electroanal. Chem. Interfacial Electrochem., 111, 111 (1980).

7. S. R. Mirrezaei, H. S. Munro, and D. Parker, Synth. Metals, 26, 169 (1988).

8. T. Ohsaka, Y. Ohnuki, N. Oyama, G. Katagiri, and K. Kamisako, J. Electroanal. Chem. Interfacial Electrochem., 161, 399 (1984).

9. Y. Gao, S. Li, Z. Xue, and D. Guo, Synth. Metals, 16, 305 (1986).

10. J. Tang, X. Jing, B. Wang, and F. Wang, Synth. Metals, 24, 231 (1988).

11. T. Hjertberg, W. R. Salaneck, I. Lundstrom, N. L. D. Somasiri, and A. G. MacDiarmid, J. Polym. Sci., Polym. Lett. Ed., 23, 503 (1985).

12. T. Hagiwara, T. Demura, and K. Iwata, Synth. Metals, 18, 317 (1987).

13. T. Hjertberg, M. Sandberg, O. Wennerstrom, and I. Lagerstedt, Synth. Metals, 21, 31 (1987).

14. R. H. Baughman, J. F. Wolf, H. Eckhardt, and L. W. Shacklette, Synth. Metals, 25, 121 (1988).

15. T. Hagiwara, M. Yamaura, and K. Iwata, Synth. Metals, 26, 195 (1988).

16. W. R. Salaneck, I. Lundstrom, T. Hjertberg, C. B. Duke, E. Conwell, A. Paton, A. G. MacDiarmid, N. 
L. D. Somasiri, W. S. Huang, and A. F. Richter, Synth. Metals, 18, 291 (1987).

17. P. Snauwaert, R. Lazzaroni, J. Riga, and J. J. Verbist, Synth. Metals, 21, 181 (1987).

18. H. S. Munro, D. Parker, and J. G. Eaves, "Electronic Properties of Conjugated Polymers," H. Kuzmany, M. Mehring, and S. Roth, Ed., Springer, Berlin, 1987, p 257.

19. K. Urdal, M. A. Hasan, J. O. Nilsson, W. R. Salaneck, I. Lundstrom, A. G. MacDiarmid, A. Ray, and A. Angelopoulos, in "Electronic Properties of Conjugated Polymers," H. Kuzmany, M. Mehring, and S. Roth, Ed., Springer, Berlin, 1987, p 262.

20. A. F. Diaz, J. I. Castillo, J. A. Logan, and W. Y. Lee,
J. Electroanal. Chem., 129, 115 (1981).

21. C. Menardo, M. Nechtschein, A. Rousseau, J. P. Travers, and P. Hany, Synth. Metals, 25, 311 (1988).

22. E. T. Kang, H. C. Ti, and K. G. Neoh, Polym. J., 20, 845 (1988).

23. T. A. Skotheim, M. I. Florit, A. Melo, and W. E. O'Grady, Phys. Rev. B, 30, 4846 (1984).

24. A. J. Epstein and A. G. MacDiarmid, J. Mol. Electron., 4, 161 (1988).

25. T. Hagiwara, M. Yamaura, and K. Iwata, Synth. Metals, 25, 243 (1988).

26. G. E. Muilenberg, Ed., "Handbook of X-Ray Photoelectron Spectroscopy," Perkin-Elmer Corp., 1977 , p 56. 